Check for updates

Cite this: RSC Adv., 2017, 7, 24321

Received 2nd March 2017 Accepted 11th April 2017

DOI: $10.1039 / c 7 r a 02576 a$

rsc.li/rsc-advances

\section{Effects of rhamnolipids on the cell surface characteristics of Sphingomonas sp. GY2B and the biodegradation of phenanthrene $\uparrow$}

\author{
Weijia Lin, ${ }^{a}$ Shasha Liu, ${ }^{a}$ Le Tong, ${ }^{a}$ Yumei Zhang, ${ }^{a}$ Jing Yang, ${ }^{a}$ Weiting Liu, (D) ${ }^{a}$ \\ Chuling Guo, ${ }^{\text {abc }}$ Yingying Xie, ${ }^{a}$ Guining Lu ${ }^{\text {ac }}$ and Zhi Dang ${ }^{a b c}$
}

A number of biosurfactants have been applied in the bioremediation of contaminated environment; however, their impact on bioremediation is controversial. The present study was focused on the effects of biosurfactants on the biodegradation capability and the interaction of biosurfactants with bacterial cells. The impacts of the widely used biosurfactant rhamnolipids on a typical phenanthrene-degrading Sphingomonas sp. GY2B were examined. It was observed that the removal percentages of phenanthrene decreased when rhamnolipids were added in higher than 1 critical micelle concentration (CMC); however, no difference in the removal percentages was observed after $24 \mathrm{~h}$ treatment when the rhamnolipids were added in lower than 1 CMC. This may be due to the fact that higher concentrations (above $1 \mathrm{CMC}$ ) of rhamnolipids cause the sequestration of PAHs into surfactant micelles. This phenomenon was further confirmed by the results of FTIR analysis. SEM images and the zeta potential test further proved that the addition of rhamnolipids decreased the cell surface hydrophobicity (CSH) and reduced the amount of filamentary materials. The ratio of saturated fatty acids to unsaturated fatty acids (sat/unsat) of cells showed a decreasing trend from 38.50 to 26.10 in the absence of rhamnolipids. However, no obvious difference was observed with 1 CMC of rhamnolipids (35.34 and 33.77 at $24 \mathrm{~h}$ and $48 \mathrm{~h}$, respectively), indicating that rhamnolipids may not enhance the membrane fluidity and transmembrane transport of phenanthrene. Overall, the addition of rhamnolipids in a concentration above its CMC could cause a lag period in the biodegradation of phenanthrene. Therefore, it is necessary to determine the optimal dosage of the biosurfactants to enhance the surfactant-amended remediation applications involving the biodegradation of PAHs.

\section{Introduction}

Polycyclic aromatic hydrocarbons (PAHs) have become a global environmental concern due to their mutagenic and carcinogenic effects on both humans and the ecosystem. Most PAHs are formed during the incomplete combustion and pyrolysis of fossil fuels and biomass, as well as the coking process. ${ }^{\mathbf{1 , 2}}$ The removal of PAHs from soils and aquifers by natural attenuation mechanisms or traditional remediation efforts is often limited by their poor water solubility. Biodegradation has been proven to be one of the most economical and environmentally applicable methods for the remediation of $\mathrm{PAH}$-contaminated sites.

${ }^{a}$ School of Environment and Energy, South China University of Technology, Guangzhou 510006, PR China. E-mail: clguoscut@gmail.com

${ }^{b}$ The Key Lab of Pollution Control and Ecosystem Restoration in Industry Clusters, Ministry of Education, Guangzhou 510006, PR China

${ }^{c}$ Guangdong Provincial Engineering and Technology Research Center for Environmental Risk Prevention and Emergency Disposal, Guangzhou 510006, PR China

$\dagger$ Electronic supplementary information (ESI) available. See DOI: $10.1039 / \mathrm{c} 7 \mathrm{ra02576a}$
However, the bioavailability of PAHs has been a major limiting factor for the conventional biodegradation of PAHs. ${ }^{3}$

Micellar surfactant solutions have been studied and assessed as efficient agents for enhancing the aqueous solubility of PAHs, thus increasing the bioavailability of PAHs for their biodegradation. ${ }^{4-6}$ However, in recent years, the negligible or even negative effects of surfactants on the biodegradation of PAHs have also been reported. The addition of some synthetic surfactants can actually inhibit the biodegradation of PAHs via toxic interactions, stimulation of surfactant degraders, or sequestration of PAHs into surfactant micelles. ${ }^{7,8}$

Biosurfactants with the ability to solubilize hydrophobic organic contaminants (HOCs) have shown several additional advantages over synthetic surfactants, which make them good candidates in bioremediation applications. Among the various categories of biosurfactants, the glycolipid biosurfactants "rhamnolipids" stand apart. Rhamnolipids are the biosurfactants produced by Pseudomonas species. ${ }^{9}$ The rhamnolipids are composed of a rhamnose moiety (hydrophilic glycon part) head group and a lipid moiety (hydrophobic glycon part) tail group, which are linked via an $O$-glycosidic linkage. The 
capabilities of rhamnolipids to solubilize organic matter and promote biodegradation have been reported. For example, Zhang et al. ${ }^{10}$ studied the effect of rhamnolipids on the dissolution, bioavailability, and biodegradation of phenanthrene, and the results showed that two different types of rhamnolipids increased the solubility and the rate of degradation of phenanthrene. Churchill et al. ${ }^{11}$ showed that rhamnolipids (a class of glycolipid) obtained from bacteria in combination with oleophilic fertilizer were capable of increasing the degradation rate of hexadecane, benzene, toluene, $o$ - and $p$-cresol, and naphthalene in both the aqueous-phase and soil bioreactors; moreover, they further reported increased rates of the biodegradation of aliphatic and aromatic hydrocarbons by pure bacterial cultures via the same treatment. ${ }^{\mathbf{1 2}}$ The rapid removal of rhamnolipids from the environment to avoid secondary pollution makes their application much safer and wider. ${ }^{\mathbf{1 3}}$

In addition, some studies have reported the interaction of biosurfactants with bacterial cells, and it was found that the addition of surfactants may either increase or decrease the cell surface hydrophobicity (CSH), therefore posing a substantial influence on the uptake and biodegradation of hydrophobic pollutants. A recent report revealed $^{\mathbf{1 4}}$ that the addition of rhamnolipids promoted the surfactant-mediated-uptake of phenanthrene by bacterial strain P-CG3, but inhibited the uptake by bacterial strain BUM through direct contact because rhamnolipids reduced the $\mathrm{CSH}$ of BUM. This indicates that the effects of biosurfactants on the biodegradation are dependent on the interactions not only between the surfactants and PAHs, but also between the surfactants and PAH-degrading microorganisms.

Therefore, it is crucial to know the biological effects of biosurfactants on $\mathrm{PAH}$ degrading bacteria to better elucidate the underlying mechanisms of surfactant-mediated bioremediation. The present study was aimed at investigating the effects of rhamnolipids on PAH degrading microorganisms, and their implications on the biodegradation of phenanthrene (Phe). The Sphingomonas sp. GY2B strain, a typical Phe-degrading bacteria isolated from oil-contaminated soils, was chosen for this study. ${ }^{15}$ Rhamnolipids were selected to investigate (i) their effects on the biodegradation of phenanthrene by Sphingomonas sp. GY2B and the bacterial growth and (ii) the potential mechanisms of the effects based on modifications of microbial surface properties (cell hydrophobicity, cell morphology, fatty acid composition, and functional groups).

\section{Materials and methods}

\subsection{Chemicals}

Phenanthrene (purity $\geq 98 \%$ ) was obtained from Sigma Aldrich Chemical Company. HPLC-grade methanol was obtained from Shanghai Anpel Scientific Instrument Co., Ltd. All solutions were prepared with Milli-Q ${ }^{\circledR}$ water (Cambridge Isotope Laboratories, 99.9\% purity). Methanol and acetone were obtained from ANPEL Laboratory Technologies (Shanghai, China) Inc. Rhamnolipids (purity $\geq 98 \%$ ) were obtained from Huzhou Zijin Biological Technology Company. The critical micelle concentration (CMC) of rhamnolipids in mineral salt medium (MSM) was $56 \mathrm{mg} \mathrm{L}^{-1}$ (CMC values of rhamnolipids were measured at
$25{ }^{\circ} \mathrm{C}$ by the Wilhelmy plate technique using a QZBY-1 model tensiometer). All other reagents $\left(\mathrm{KH}_{2} \mathrm{PO}_{4}, \mathrm{~K}_{2} \mathrm{HPO}_{4}\right.$, and $\left.\mathrm{CaCl}_{2}\right)$ were of the highest purity available.

The mineral salt medium (MSM) consisted of the following materials (per liter): $5 \mathrm{~mL}$ phosphate buffer solution $\left(\mathrm{KH}_{2} \mathrm{PO}_{4}\right.$, $8.5 \mathrm{~g} \mathrm{~L}^{-1} ; \mathrm{K}_{2} \mathrm{HPO}_{4} \cdot \mathrm{H}_{2} \mathrm{O}, 21.75 \mathrm{~g} \mathrm{~L}^{-1} ; \mathrm{Na}_{2} \mathrm{HPO}_{4} \cdot 12 \mathrm{H}_{2} \mathrm{O}, 33.4 \mathrm{~g}$ $\mathrm{L}^{-1}$; and $\left.\mathrm{NH}_{4} \mathrm{Cl}, 5.0 \mathrm{~g} \mathrm{~L}^{-1}\right), 3.0 \mathrm{~mL} \mathrm{MgSO}_{4}$ solution $\left(22.5 \mathrm{~g} \mathrm{~L}^{-1}\right)$, $1.0 \mathrm{~mL} \mathrm{FeCl}_{3}$ solution $\left(0.25 \mathrm{~g} \mathrm{~L}^{-1}\right), 1.0 \mathrm{~mL} \mathrm{CaCl}_{2}$ solution $(36.4 \mathrm{~g}$ $\left.\mathrm{L}^{-1}\right)$, and $1.0 \mathrm{~mL}$ trace element solution $\left(\mathrm{MnSO}_{4} \cdot \mathrm{H}_{2} \mathrm{O}, 39.9 \mathrm{mg}\right.$ $\mathrm{L}^{-1} ; \mathrm{ZnSO}_{4} \cdot \mathrm{H}_{2} \mathrm{O}, 42.8 \mathrm{mg} \mathrm{L} \mathrm{L}^{-1}$, and $\left(\mathrm{NH}_{4}\right)_{6} \mathrm{Mo}_{7} \mathrm{O}_{24} \cdot 4 \mathrm{H}_{2} \mathrm{O}$, $\left.34.7 \mathrm{mg} \mathrm{L}^{-1}\right)$. The medium solution was prepared with distilled water and autoclaved at $1 \mathrm{~atm}$ for $15 \mathrm{~min}$. The $\mathrm{pH}$ value was adjusted to 7.2 using $5 \mathrm{~mol} \mathrm{~L}^{-1} \mathrm{HCl}$ and $\mathrm{NaOH}$ solutions.

\subsection{Biodegradation tests}

Sphingomonas sp. GY2B (GenBank DQ 139343) was isolated from polycyclic aromatic hydrocarbon (PAH)-contaminated soils. ${ }^{15}$ Bacterial strain GY2B was harvested in exponential phase in MSM with phenanthrene as its sole carbon source. Before the degradation experiment, the strain was washed three times with $0.02 \mathrm{M}$ phosphate buffer solution (PBS) $(0.02 \mathrm{M}$ $\mathrm{K}_{2} \mathrm{HPO}_{4}$ and $0.02 \mathrm{M} \mathrm{KH}_{2} \mathrm{PO}_{4}$ ) and then re-suspended in MSM to obtain the cell concentration of about $10^{7}$ colony-forming unit (CFU) $\mathrm{mL}^{-1}$. Phenanthrene solution was added to each Erlenmeyer flask to obtain the final concentration of $100 \mathrm{mg} \mathrm{L}^{-1}$. Then, biosurfactant-MSM and cell suspension were added to the flasks one by one after the solvent (acetone) evaporated from the bottom surface. The concentrations of rhamnolipids were set at $0,0.2,1$, and 4 times its CMC. Blank treatments, with the same amount of PHE but without inoculation, were prepared to account for the abiotic loss. All the tested flasks were incubated in a reciprocating shaker at $150 \mathrm{rpm}$ and $30{ }^{\circ} \mathrm{C}$ in the dark to avoid photodegradation. Residue phenanthrene of each group was detected at expected time intervals. All the samples were performed in triplicate.

Residual phenanthrene in the reaction system $(20 \mathrm{~mL})$ was extracted with methanol using an ultrasonic washer, then transferred to a $50 \mathrm{~mL}$ volumetric flask, and diluted to the mark using methanol. All the samples were filtrated through a 0.22 $\mu \mathrm{m}$ filter prior to HPLC analysis. The removal efficiency of phenanthrene was calculated using the following equation:

$$
\mathrm{Re}=\frac{\left(A_{0}-A\right)}{A_{0}} \times 100 \%
$$

where $A_{0}$ is the characteristic peak area of the blank and $A$ is the characteristic peak area of the degrading system in the absence or presence of rhamnolipids.

\subsection{Effects of rhamnolipids on the CSH of PAH degrading bacteria}

After the biodegradation experiment carried out for $24 \mathrm{~h}$, as described in the Section 2.2, cells of GY2B were harvested by centrifugation (12 $000 \mathrm{~g}$ for $5 \mathrm{~min}$ ), washed 3 times with MSM, and resuspended in $3 \mathrm{~mL}$ of MSM. The OD of the aqueous phase of the cell suspension was measured at $600 \mathrm{~nm}$ and obtained as $T_{0}$. After this, $1 \mathrm{~mL}$ of $n$-hexadecath was added, and the mixture 
was vortexed for $1 \mathrm{~min}$ and incubated for an additional $15 \mathrm{~min}$ at room temperature. The OD of the aqueous phase was measured at $600 \mathrm{~nm}$ and obtained as $T$. The cell surface hydrophobicity was expressed as percent cells transferred to the hydrocarbon phase by measuring the OD of the aqueous phase before and after mixing and was calculated using the following formula:

$$
\mathrm{CSH}(\%)=\frac{\left(T_{0}-T\right)}{T_{0}} \times 100
$$

\subsection{Biomorphology affected by rhamnolipids}

The morphological changes of GY2B, with and without rhamnolipids, were characterized by SEM (Carl Zeiss Jena Merlin). Cells cultivated with different concentrations of rhamnolipids were conducted in the same conditions as above mentioned in Section 2.2. The control group was cells cultivated with 1 CMC rhamnolipids without phenanthrene. After $24 \mathrm{~h}$ and $48 \mathrm{~h}$ cultivation, samples were taken out and subjected to a series of pre-treatment processes including rinsing with PBS, fixation with glutaraldehyde, gradient dehydration with ethanol, replacement with tertiary butyl alcohol, and freeze drying. After this, the sample powders were coated with gold prior to the SEM analysis.

\subsection{Zeta potential measurement}

After undergoing the biodegradation experiment as described in Section 2.2, cells of GY2B were harvested by centrifugation (12 $000 \mathrm{~g}$ for $5 \mathrm{~min}$ ), washed 3 times with PBS, and shaken using an ultrasonic washer for 10 minutes. The control group was cells cultivated with 1 CMC rhamnolipids without phenanthrene. Zeta potentials were immediately measured at room temperature via laser Doppler velocimetry using a zetaphoremeter 4.20 (CAD Instrumentation, Les Essarts-leRoi, France) equipped with a rectangular glass electrophoresis cell, a CCD camera, and a viewing system.

\subsection{Characterization of the cell surface functional groups}

After undergoing biodegradation experiments for $24 \mathrm{~h}$ and $48 \mathrm{~h}$ with the concentrations of rhamnolipids as $0,0.2$, and 1 times its CMC, cells of GY2B were harvested. The bacteria were washed three times with $\mathrm{PBS}(\mathrm{pH}$ 7.2) to remove all the interfering substances and dried in a freeze drier at $-50{ }^{\circ} \mathrm{C}$ for $24 \mathrm{~h}$. The dried cells were used to characterize the cell surface functional groups.

After the samples were prepared as $\mathrm{KBr}$ pellet discs, the functional groups of the samples were analyzed using a Fourier transform infrared (FTIR) spectrometer (Bruker Vertex33, Germany). The samples were investigated between 400 and 4000 wavenumber under 100 scans with the resolution of $7.5 \mathrm{px}^{-1} .^{16}$ Spectral processing was carried out to remove $\mathrm{CO}_{2}$ and any noise from the spectrum, and finally, the spectra were normalized. The FTIR spectra were analyzed using an OMNIC software. All the spectra were plotted using the same scale on the $Y$ axis (e.g. transmittance).

\subsection{Fatty acid extraction and analysis}

To assess the effect of surfactants on the entire cell-derived fatty acid methyl ester composition, rhamnolipids were added to the MSM at the final concentrations of 0 CMC and 1 CMC. Biosurfactant-dosed cultures were incubated in the dark at $30{ }^{\circ} \mathrm{C}$ while shaking at $150 \mathrm{rpm}$. In brief, the fatty acid composition of GY2B cells was determined after $2 \mathrm{~h}, 24 \mathrm{~h}$, and $48 \mathrm{~h}$ post inoculation. Strain GY2B cells were harvested by centrifugation $(3000 \mathrm{~g})$ at $25{ }^{\circ} \mathrm{C}$ for $10 \mathrm{~min}$. The cell pellets (approximately $3 \mathrm{mg}$ of the cell wet weight) were washed with 10 $\mathrm{mL}$ of dimethylformamide to remove any residual phenanthrene. The cells were then washed twice with MSM to remove any surfactant residues and centrifuged. The cells were weighed and transferred into a centrifugal glass tube. GY2B cells were methylated at $85{ }^{\circ} \mathrm{C}$ for $60 \mathrm{~min}$ in $2 \mathrm{~mL}$ of $5 \% \mathrm{HCl}-$ methanol solution, $3 \mathrm{~mL}$ of $1: 1 \mathrm{v} / \mathrm{v}$ chloroform : methanol, and $100 \mu \mathrm{L}$ of nonadecanoic acid-methyl ester as the internal standard. Then, the abovementioned mixture was extracted with $1 \mathrm{~mL}$ of $n$ hexane and shaken for $2 \mathrm{~min}$. The supernatant fluid was filtered by a $0.45 \mu \mathrm{m}$ filtration membrane and tested.

Fatty acids were separated and quantified using a GC-MS 6890-5975 system (Agilent Technologies, Palo Alto, CA, USA) equipped with a TG-5MS capillary column (5\% phenyl methylsiloxane) with the dimensions of $30 \mathrm{~m} \times 0.25 \mathrm{~mm}$ and a film thickness of $0.25 \mu \mathrm{m}$. An initial temperature of $80{ }^{\circ} \mathrm{C}$ was maintained for $1 \mathrm{~min}$, and then, the temperature was increased to $200{ }^{\circ} \mathrm{C}$ at the rate of $10{ }^{\circ} \mathrm{C} \min ^{-1}, 250{ }^{\circ} \mathrm{C}$ at the rate of $5{ }^{\circ} \mathrm{C}$ $\min ^{-1}, 270{ }^{\circ} \mathrm{C}$ at the rate of $2{ }^{\circ} \mathrm{C} \min ^{-1}$, and was then maintained at $270{ }^{\circ} \mathrm{C}$ for $3 \mathrm{~min}$. Helium was used as the carrier gas with the flow rate of $1.2 \mathrm{~mL} \mathrm{~min}^{-1}$. The injector temperatures were $290{ }^{\circ} \mathrm{C}$. The mass spectrometer was operated in the electron impact (EI) mode at $70 \mathrm{eV}$ in the scan range of 30-400 amu.

\subsection{Statistical analysis}

The data were analyzed using Origin 8.0. Mean values and standard deviations were calculated.

\section{Results and discussion}

\subsection{Effect of rhamnolipids on the biodegradation of phenanthrene}

The removal efficiencies of phenanthrene by strain GY2B with rhamnolipids are shown in Fig. 1. The removal efficiencies of phenanthrene had no difference when the concentration of rhamnolipids was 0.2 CMC and 0 CMC. The removal efficiencies decreased when the concentration of rhamnolipids was above 1 CMC. For example, the removal efficiencies of phenanthrene in the biodegradation system with $1 \mathrm{CMC}$ and 4 CMC rhamnolipids were $24.65 \%$ and $21.20 \%$, respectively, at $24 \mathrm{~h}$, compared to that at $0 \mathrm{CMC}$ of rhamnolipids (52.93\%). However, phenanthrene was almost completely removed at $48 \mathrm{~h}$ in all the cases. This suggested that the rhamnolipids caused a lag period in the biodegradation of phenanthrene.

Makkar and Rockne ${ }^{17}$ found that surfactant addition can actually inhibit PAH biodegradation via toxic interactions, stimulation of surfactant degraders, or sequestration of PAHs 


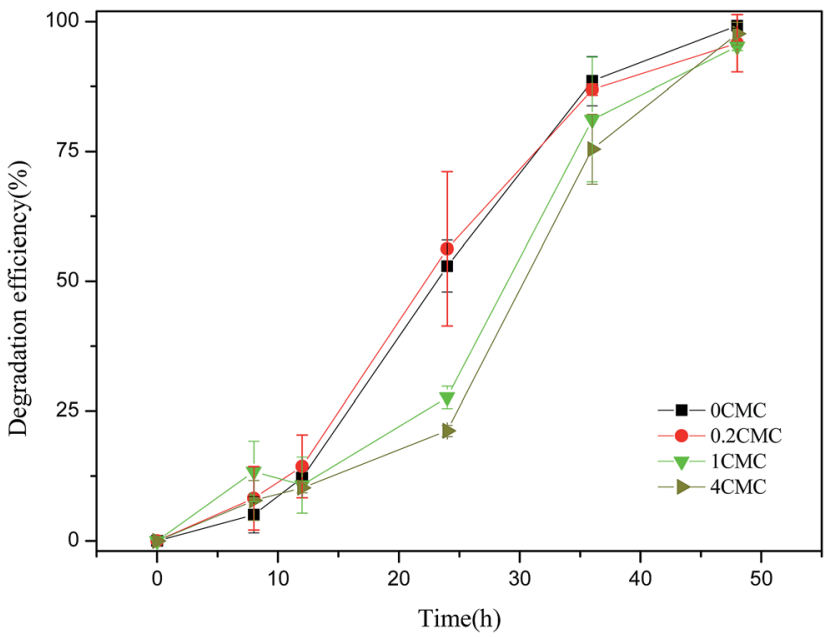

Fig. 1 Effects of rhamnolipids on the biodegradation of phenanthrene by Sphingomonas sp. GY2B.

into surfactant micelles. Shin et al. ${ }^{18}$ observed that the solubilizing capacity of rhamnolipids for phenanthrene decreased as the morphology changed from lamella to vesicles to micelles, and not all the solubilized phenanthrene was bioavailable to the microorganisms. Therefore, phenanthrene present in the micellar phase (above the CMC) may replenish the aqueousphase PAHs as they are depleted by biodegradation, a result also reported by Zhang and Miller. ${ }^{19}$

\subsection{Effect of rhamnolipids on the CSH of GY2B}

The effectiveness of surfactants on the biodegradation of hydrophobic pollutants can be affected via the modification of cell surface hydrophobicity. ${ }^{\mathbf{2 0 2} 21}$ The addition of surfactants may either increase or decrease the $\mathrm{CSH}$ and thus pose an important influence on the uptake and biodegradation of hydrophobic pollutants. ${ }^{14}$ Hence, the effects of rhamnolipids on the CSH of GY2B were tested, and the results are shown in Fig. 2 .

The values of $\mathrm{CSH}$ were $41.88 \%$ and $44.37 \%$ at $24 \mathrm{~h}$ and $48 \mathrm{~h}$, respectively, in the absence of rhamnolipids. The CSH values were $38.03 \%, 36.24 \%$, and $28.30 \%$ corresponding to the rhamnolipid concentrations of $0.2 \mathrm{CMC}, 1 \mathrm{CMC}$, and $4 \mathrm{CMC}$ at $24 \mathrm{~h}$, respectively. Although the $\mathrm{CSH}$ did not significantly correspond with the phenanthrene biodegradation efficiency when the rhamnolipids concentration was $1 \mathrm{CMC}$, the addition of rhamnolipids would generally decrease the CSH of the cell surface and thus affect the uptake of phenanthrene.

Some researchers have also found that the addition of rhamnolipids decreased the $\mathrm{CSH}$. Ahimou et al. ${ }^{22}$ found that the sorption of lipopeptides decreased the $\mathrm{CSH}$ of two B. subtilis strains with a hydrophobic cell surface. Zhao et al. ${ }^{\mathbf{1 4}}$ investigated the effects of rhamnolipids produced by Pseudomonas aeruginosa ATCC9027 on the cell surface hydrophobicity (CSH) and the biodegradation of phenanthrene by Bacillus subtilis BUM. The results showed that rhamnolipids significantly reduced the $\mathrm{CSH}$ of the hydrophobic BUM and inhibited the uptake through direct contact by BUM, resulting in a noticeable lag period in the

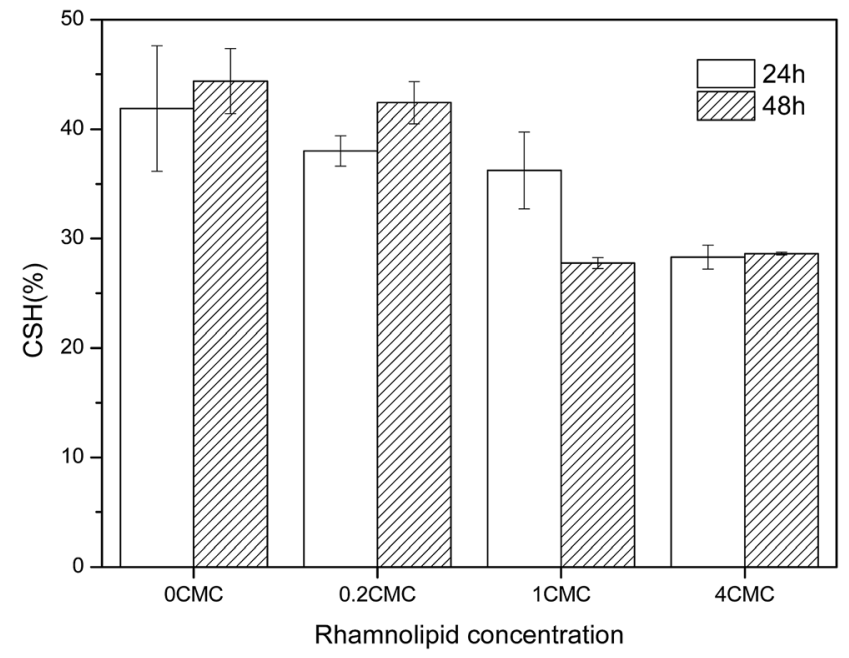

Fig. 2 Effects of rhamnolipids on the CSH of Sphingomonas sp. GY2B.

biodegradation. The change of microbial CSH may be correlated with the sorption of hydrophobic pollutants and some hydrophobic substances formed by bacteria, and rhamnolipids would affect the hydrophobic substances by absorbing to the cell surface. This reason has been illustrated in Section 3.3.

\subsection{SEM characterization}

The cell membrane skeleton comprises a phospholipid bilayer and protein, in which the phospholipid molecules move in various ways and provide membrane fluidity. The plasma membrane plays an important role in separating the intracellular and extracellular environments, providing an anisotropic fluid phase to support proteins and regulate molecular transport. ${ }^{23}$ The integrity of the cellular structure was important to the activities of the bacteria. Thus, SEM observation was carried out to determine whether rhamnolipids carried the risk of membrane damage.

In Fig. 3A, it can be seen that despite having a ravine-like rough surface, herein, bacteria showed a mellow and full structure. With the increasing concentration of rhamnolipids, SEM images showed that the microorganisms maintained the integrity of the microbial structure as well as membrane morphology, which were indicative of the mildness of this additive. Liu et $a .^{24}$ observed the GY2B cell morphology via SEM and found that the GY2B cells grown in TritonX-100 shriveled and had a rough surface, along with diffused cytoplasm in the core zone of the cells. Moreover, the cell morphology was more severely affected by Brij30, with more deformed cells and a seriously disrupted membrane. It, thus, appeared that rhamnolipids were milder than other chemosynthetic surfactants, and this was the reason why phenanthrene could be completely degraded at $48 \mathrm{~h}$ with rhamnolipids although the degradation efficiencies were low at $24 \mathrm{~h}$ and $36 \mathrm{~h}$.

In addition, filamentary materials appeared when GY2B was treated with $0 \mathrm{CMC}$ or $0.2 \mathrm{CMC}$ rhamnolipids at $24 \mathrm{~h}$ (Fig. 3A$\mathrm{B})$, whereas they decreased or disappeared with higher doses of rhamnolipids (Fig. 3C-E). Moreover, the filamentary materials 

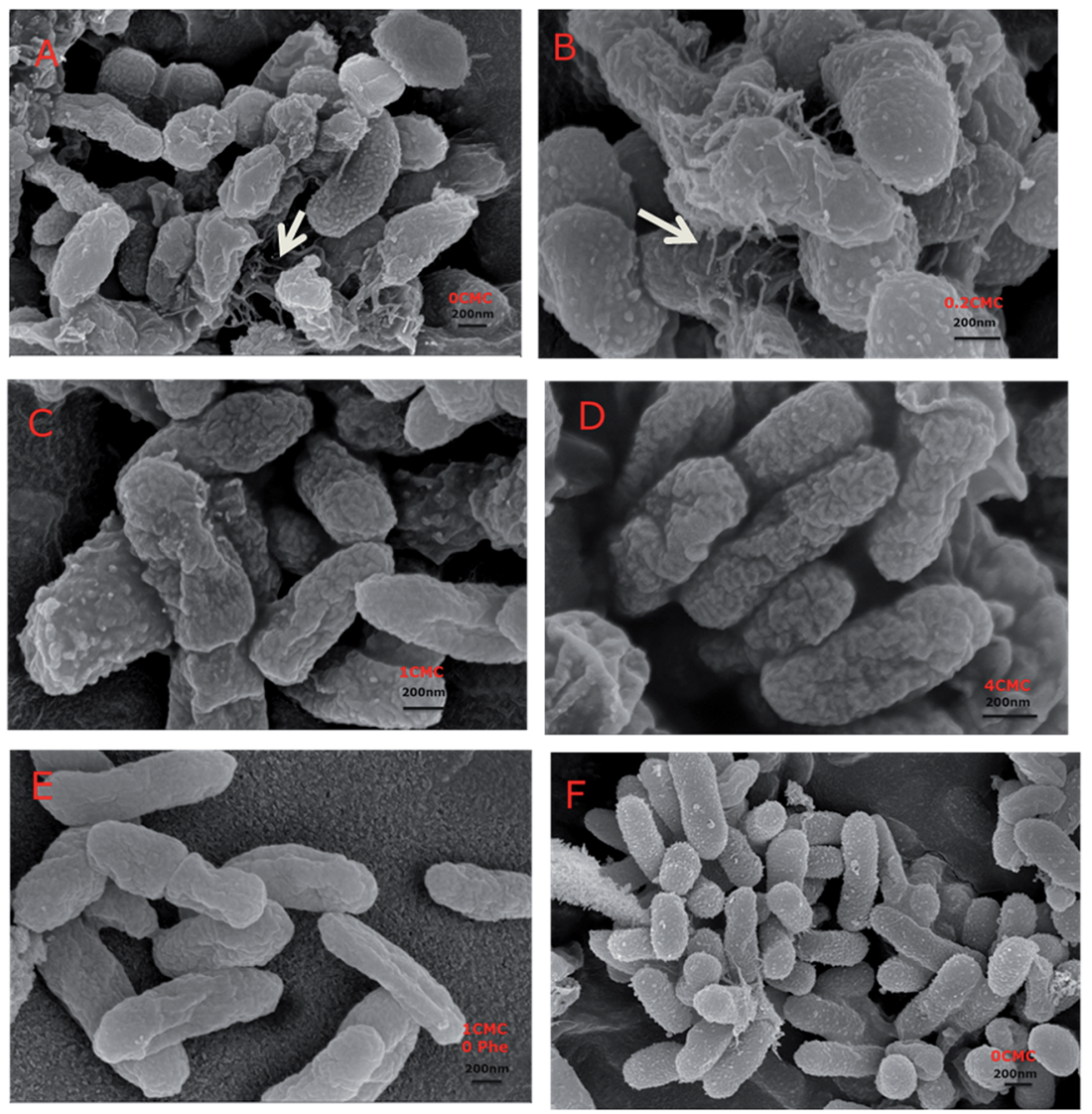

Fig. 3 SEM images of Sphingomonas sp. GY2B showing (A-D) cells in the presence of 0 CMC, 0.2 CMC, 1 CMC, and 4 CMC rhamnolipids and phenanthrene at $24 \mathrm{~h}$, (E) cells in the presence of $1 \mathrm{CMC}$ rhamnolipids without phenanthrene at $24 \mathrm{~h}$, and (F) cells in the absence of rhamnolipids with phenanthrene at $48 \mathrm{~h}$.

decreased after treatment without rhamnolipids after $48 \mathrm{~h}$ (Fig. 3F). These filamentary materials were also observed by She et al. ${ }^{25}$ They investigated the effects of nanobiomaterials (NBC) on the phenanthrene degrading strain Sphingomonas sp. GY2B and found that filamentary materials existed under all the conditions, connecting cells with cells or NBC. These filamentary materials belong to extracellular polymeric substances (EPS). EPS can bind with many exogenous organic compounds and inorganic ions and form a protective barrier against many xenobiotics. ${ }^{26}$ Moreover, the differences in the functional groups lead to variations in the hydrophilicity and hydrophobicity, thus affecting the adsorption and transmission of the material to EPS. ${ }^{27}$ Hence, EPS will positively affect the uptake of the nutrients ${ }^{28}$ such as $\mathrm{NH}_{4}{ }^{+}-\mathrm{N}$ and $\mathrm{PO}_{4}{ }^{3-}-\mathrm{P}$.

Moreover, the filamentous materials connected either the cells with cells or cells with phenanthrene. EPS are the important components of activated sludge for the removal of pollutants from wastewater, and a number of studies have reported the high adsorption capacity of EPS for heavy metals. ${ }^{29-33}$ EPS have also been reported to have hydrophobic moieties, ${ }^{34}$ which should have strong affinity for hydrophobic pollutants such as PAHs, and the binding of EPS with PHE was dominated by the hydrophobic interactions. ${ }^{35}$ It was speculated that the filamentous materials secreted by GY2B would play an important role in the adsorption of phenanthrene by bacterial strains and the phenanthrene biodegradation efficiency. In the present study, the filamentous materials disappeared when high dose of rhamnolipids was added (Fig. 3C-D), and the potential of rhamnolipids for reducing EPS has also been reported, ${ }^{36-38}$ which indicated that the addition of rhamnolipids did not have a positive impact on the biodegradation of phenanthrene.

Moreover, a few studies have reported that a wide variety of bacteria formed hydrophobic substances on the cell surface in the presence of low-water soluble substrates, resulting in the increase of CSH. For example, growth on anthracene led to more hydrophobic mycolic acids in the cell envelope, resulting in higher CSH of Mycobacterium frederiksbergense. ${ }^{39}$ B. subtilis and $P$. aeruginosa secreted biosurfactant-like substances that enhanced the $\mathrm{CSH}$, resulting in higher uptake and utilization of pyrene. ${ }^{40}$ The reduction of EPS may be one of the reasons for the decrease of the $\mathrm{CSH}$ with the addition of $1 \mathrm{CMC}$ and $4 \mathrm{CMC}$ rhamnolipids.

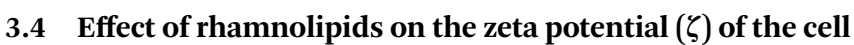 surface}

The change in the zeta potential $(\zeta)$ of the cell surface is shown in Fig. 4 . The charge of the cell surface was negative at initial time; however, the addition of biosurfactant significantly increased the $\zeta$, which was consistent with the results reported by Hua et $a .^{41}$ The zeta potential of the bacteria increased with the 


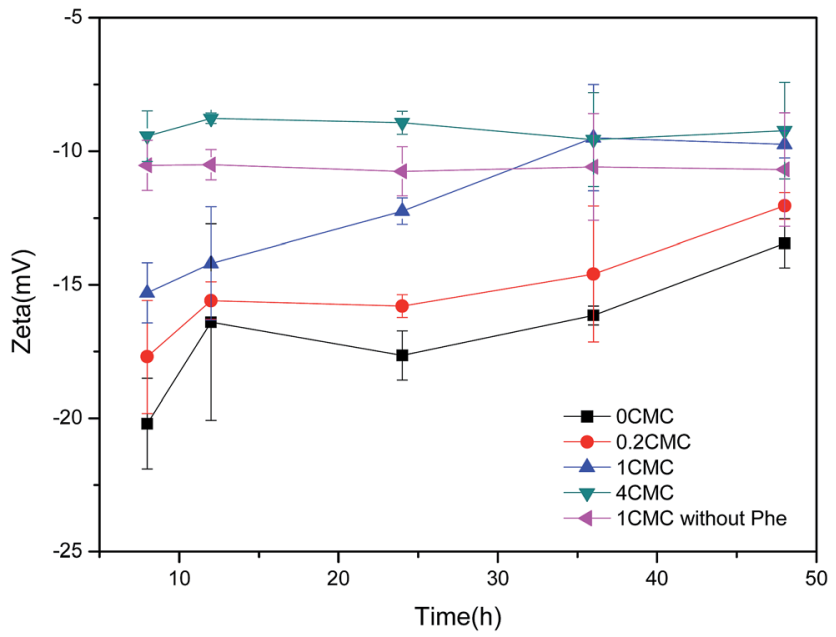

Fig. 4 Effect of rhamnolipids on the zeta potential of the cell.

increasing concentration of rhamnolipids. For example, the zeta potential increased to $-13.45,-12.05,-9.74$, and $-9.23 \mathrm{mV}$ when the rhamnolipid concentrations were $0 \mathrm{CMC}, 0.2 \mathrm{CMC}, 1$ CMC, and 4 CMC, respectively. This indicated that the addition of biosurfactant increased the positive electric charge of the cell surface. Qian et $a .^{42}$ studied that rhamnolipids may adsorb on the cell surface to form a compound with a negative charge, which would result in electrostatic repulsion with the cell wall, and thus, it would inhibit the contact between the cell and hydrophobic substrates. However, in the present study, the zeta potential increased when rhamnolipids were added; thus, the above mentioned phenomena did not exist. However, the rhamnolipids did not promote the degradation of phenanthrene, probably due to the reduction of the extracellular polymeric substances, as shown in the SEM image of GY2B. Qu et $a .^{43}$ studied that both the dissolved extracellular organic matter (dEOM) and bound extracellular organic matter (bEOM) were negatively charged as other organics in natural water, and bEOM carried much less negative surface charge than dEOM. Since the cell surface carried less extracellular polymeric substances when treated with rhamnolipids, the zeta potential was higher compared to that obtained on treatment without rhamnolipids. In addition, the zeta potential of the control group was higher than that of the group treated with 1 CMC rhamnolipids and phenanthrene; thus, the sorption of phenanthrene with the negative charge on the cell surface would decrease the zeta potential. Because the rhamnolipids solubilized phenanthrene and decreased the $\mathrm{CSH}$, less phenanthrene absorbed to the cell surface, which led to the increase in the zeta potential. After this, phenanthrene degraded, and the extracellular polymeric substances also gradually fell off, which resulted in the higher zeta potential, which was consistent with the results of SEM.

\subsection{Effect of rhamnolipids on the fatty acid composition of the strain GY2B}

Alteration in the membrane fluidity has been regarded as one of the most important adaptive mechanisms in bacteria.
Therefore, modifications in the composition of the membrane fatty acids played a very important role. These changes were helpful for microorganisms as they stabilized the fluidity of their membranes when exposed to stress factors such as HOCs and surfactants. ${ }^{44}$

The fatty acid compositions of GY2B cells under 0 CMC and 1 CMC of rhamnolipids are shown in Table 1 . The data are presented as the percent composition of each fatty acid. For the sake of interpretation, the identified fatty acids were divided into two major groups: saturated and unsaturated.

When GY2B cells were incubated without rhamnolipids for $24 \mathrm{~h}$ and $48 \mathrm{~h}$, the total level of saturated fatty acids decreased from $97.40 \%$ to $95.61 \%$. However, there was an increase in the level of unsaturated fatty acids from $2.61 \%$ to $4.39 \%$. These changes were expressed as a ratio of saturated fatty acids to unsaturated fatty acids (sat/unsat). This ratio showed a decreasing trend from 38.50 to 26.10 . The appearance of these fatty acids may indicate changes in the membrane fluidity. $\mathrm{Li}$ and $\mathrm{Zhu}^{44}$ found that when SA01 were incubated with phenanthrene for $4 \mathrm{~h}, 6 \mathrm{~d}$, and $12 \mathrm{~d}$, the ratio of saturated fatty acids to unsaturated fatty acids (sat/unsat) showed a decreasing trend from 6.18 to 5.20. They suggested that an increased amount of unsaturated fatty acids corresponded to greater membrane fluidity, and the increased membrane fluidity enhanced the transmembrane transport of phenanthrene, which is a limiting step. When the GY2B cells were exposed to external contaminations, the corresponding physiological reactions, such as change in the fatty acid compositions and secretion of EPS, were triggered to degrade the pollutants.

When 1 CMC of rhamnolipids and $100 \mathrm{mg} \mathrm{L}^{-1}$ phenanthrene were added, the total level of saturated fatty acids was $97.25 \%$ and $97.10 \%$, and the ratio of saturated fatty acids to unsaturated fatty acids was 35.34 and 33.77 at $24 \mathrm{~h}$ and $48 \mathrm{~h}$, respectively. However, these parameters did not show obvious differences when compared to those obtained after treatment without rhamnolipids at $2 \mathrm{~h}$. The rhamnolipids did not affect the fatty acid compositions of the GY2B cells. Moreover, it may have prevented phenanthrene from coming in direct contact with the cells, such that the membrane fluidity did not increase. This was one of the reasons for the lower degradation efficiency at high concentrations of rhamnolipids compared to that obtained after treatment without rhamnolipids.

\subsection{FTIR analysis}

FTIR spectra have been widely used to determine the cell surface functional groups. ${ }^{38,45}$ Thus, the changes in the functional groups of strain GY2B, with the addition of biosurfactants, were determined by FTIR spectra in the present study. The surface functional groups of strain GY2B were assigned according to the following studies ${ }^{24,38}$ and summarized in the ESI. $\dagger$ Fig. $5 \mathrm{a}-\mathrm{b}$ shows the infrared spectrum of GY2B before and after treatment with rhamnolipids for $24 \mathrm{~h}$ and $48 \mathrm{~h}$. Results indicated that the addition of the biosurfactants changed the functional groups.

The broad and intense absorption peaks at $3500-3000 \mathrm{~cm}^{-1}$ correspond to the $\mathrm{O}-\mathrm{H}$ stretching vibrations of cellular 
Table 1 Effect of rhamnolipids on the fatty acid content (\%) of GY2B cells ${ }^{a}$

\begin{tabular}{|c|c|c|c|c|c|}
\hline \multirow[b]{2}{*}{ Fatty acids } & \multicolumn{3}{|l|}{$0 \mathrm{CMC}$} & \multicolumn{2}{|l|}{$1 \mathrm{CMC}$} \\
\hline & $2 \mathrm{~h}$ & $24 \mathrm{~h}$ & $48 \mathrm{~h}$ & $24 \mathrm{~h}$ & $48 \mathrm{~h}$ \\
\hline C11.0 & $0.03 \pm 0.01$ & $0.03 \pm 0.01$ & $0.02 \pm 0.01$ & $0.03 \pm 0.01$ & $0.04 \pm 0.00$ \\
\hline C12.0 & $1.21 \pm 0.36$ & $1.44 \pm 0.35$ & $1.32 \pm 1.18$ & $1.81 \pm 0.38$ & $1.44 \pm 0.21$ \\
\hline C14.0 & $0.76 \pm 0.38$ & $0.54 \pm 0.05$ & $0.60 \pm 0.09$ & $0.60 \pm 0.02$ & $0.63 \pm 0.04$ \\
\hline C17.0 & $0.21 \pm 0.01$ & $0.20 \pm 0.00$ & $0.19 \pm 0.01$ & $0.19 \pm 0.00$ & $0.22 \pm 0.02$ \\
\hline C18.0 & $40.60 \pm 0.40$ & $40.10 \pm 1.41$ & $39.78 \pm 2.06$ & $38.81 \pm 1.07$ & $42.05 \pm 3.09$ \\
\hline $\mathrm{C} 20.0$ & $0.35 \pm 0.02$ & $0.32 \pm 0.02$ & $0.30 \pm 0.02$ & $0.29 \pm 0.01$ & $0.33 \pm 0.02$ \\
\hline $\mathrm{C} 21.0$ & $0.06 \pm 0.00$ & $0.06 \pm 0.02$ & $0.06 \pm 0.00$ & $0.07 \pm 0.01$ & $0.07 \pm 0.01$ \\
\hline \multicolumn{6}{|l|}{ Unsaturated } \\
\hline Sat./unsat. ratio & $34.51 \pm 1.35$ & $38.50 \pm 5.80$ & $26.10 \pm 6.01$ & $35.34 \pm 3.70$ & $33.77 \pm 3.81$ \\
\hline
\end{tabular}

${ }^{a}$ The following fatty acid nomenclature was applied where the number preceding the colon indicates the total number of carbon atoms, the number following the colon indicates the number of double bonds, and the suffix designates the position of the double bonds (from the methyl end of the molecule) or the position of hydroxyl groups (from the carboxyl end of the molecule), namely, the saturated fatty acids and the unsaturated fatty acids. The standard error (SE) was calculated from the analysis of triplicate samples. The values are given as the mean \pm SE.

membranes. The peaks observed at $2450-2300 \mathrm{~cm}^{-1}$ can be attributed to the $\mathrm{C}-\mathrm{H}$ stretching vibrations of methyl, methylene, and methoxy groups. The peaks observed at 1750-1720 $\mathrm{cm}^{-1}$ are the stretching vibration of $\mathrm{C}=\mathrm{O}$ bond due to nonionic carboxyl groups $\left(-\mathrm{COOH},-\mathrm{COOCH}_{3}\right)$ and may be assigned to carboxylic acids or their esters. ${ }^{46}$ Asymmetric and symmetric stretching vibrations of ionic carboxylic groups $\left(-\mathrm{COO}^{-}\right)$appeared at $1658-1650 \mathrm{~cm}^{-1}, 1567-1540 \mathrm{~cm}^{-1}$, and $1396-1392 \mathrm{~cm}^{-1} .{ }^{47}$ The bands in the range of $1200-900 \mathrm{~cm}^{-1}$ can be assigned to the $\mathrm{C}-\mathrm{O}$ stretching vibration of carboxylic acids and alcohols. It was clear from the FTIR spectrum of GY2B that carboxyl and hydroxyl groups were abundantly present. These groups may function as proton donors. The addition of rhamnolipids caused the change of these transmittance peaks and affected the degradation efficiency.
It was worth noting that the transmittance peaks of carboxylic acids or their esters $\left(1750-1720 \mathrm{~cm}^{-1}\right)$ for GY2B could be observed, except for the microorganisms treated with phenanthrene and $1 \mathrm{CMC}$ rhamnolipids at $24 \mathrm{~h}$. Moreover, the transmittance peaks of ionic carboxylic groups (1396-1392 $\mathrm{cm}^{-1}$ ) could be observed until the microorganisms were treated for 48 h. Liu et al. ${ }^{24}$ found that $8 \mathrm{CMC}$ of Triton X-100 and Brij30 resulted in the reduction or removal of absorption peak intensities of the fatty acids or lipids from cell membrane $\left(2855 \mathrm{~cm}^{-1}\right.$ or $1736 \mathrm{~cm}^{-1}$ ). The reduction in the intensities of the functional groups may originate from the fact that they could incorporate into the cell membrane and induce the release of membrane components (such as lipids and polysaccharides) into the culture medium. However, there was no composition of fatty acid absent when GY2B was treated with rhamnolipids and
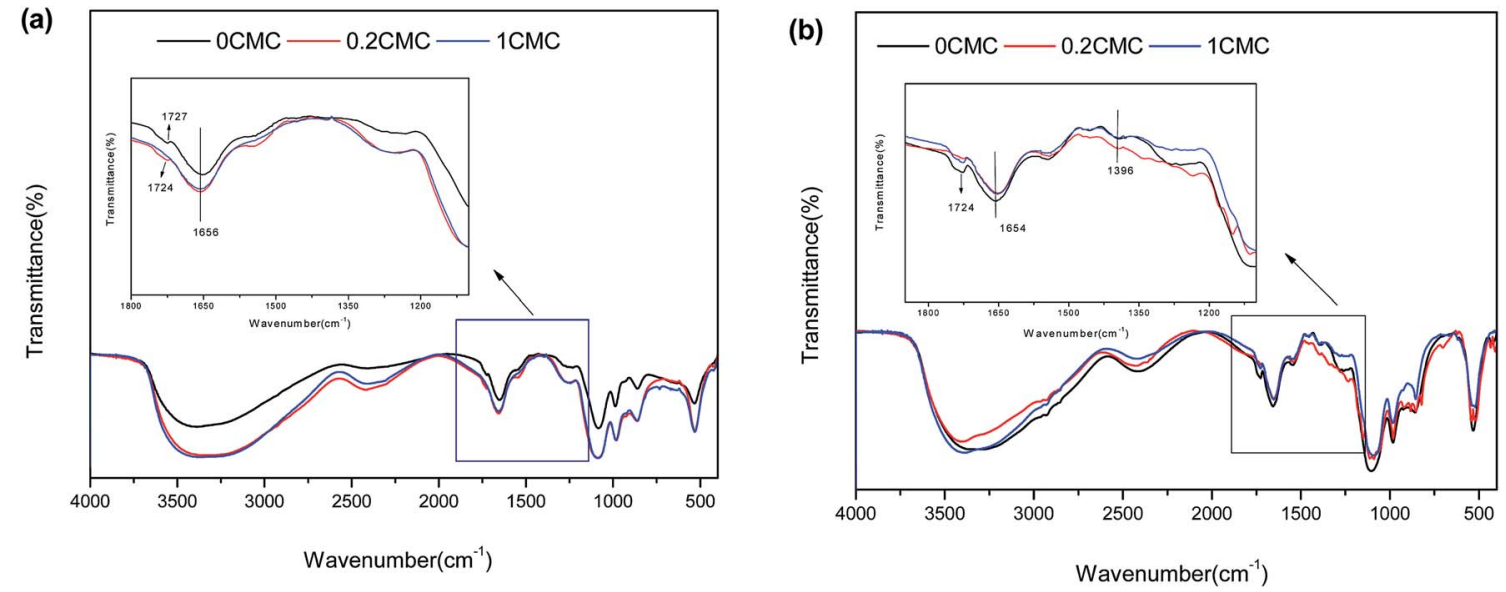

Fig. 5 FTIR spectrum of GY2B in the presence of O CMC, 0.2 CMC, and 1 CMC rhamnolipids at $24 \mathrm{~h}$ (a) and $48 \mathrm{~h}$ (b). 
phenanthrene and even the ratio of saturated fatty acids to unsaturated fatty acids did not show much difference, according to the analysis described in Section 3.5. In addition, the $\mathrm{C}=\mathrm{O}$ stretching bands at $1750-1720 \mathrm{~cm}^{-1}$ were present when GY2B was treated with phenanthrene and rhamnolipids at $48 \mathrm{~h}$. As a result, the rhamnolipids did not disrupt the cell membranes, which agreed with the previous results obtained (Section 3.3) in this study.

The $\mathrm{C}=\mathrm{O}$ stretching bands at $1750-1720 \mathrm{~cm}^{-1}$ and $1396-$ $1392 \mathrm{~cm}^{-1}$ may be correlated with the intermediates when phenanthrene was degraded by GY2B. Tao et $a .^{15}$ investigated the metabolites of phenanthrene such as 1-hydroxy-2-naphthoic acid, 1-naphthol, and salicylic acid. These intermediates contained carboxylic acid functional groups. As shown by the SEM of GY2B, some phenanthrene molecules were absorbed on the surface of the cell, and their intermediates may be residual. However, because of a lag period in the biodegradation of phenanthrene at high concentrations of rhamnolipids, there were fewer intermediates and these were not detected at $24 \mathrm{~h}$.

\section{Conclusions}

The effects of rhamnolipids on the biodegradation of phenanthrene by Sphingomonas sp. GY2B depended on the concentration of rhamnolipids. Rhamnolipids did not affect the degradation of phenanthrene when the concentration of rhamnolipids was below $1 \mathrm{CMC}$. However, it caused a lag period in the biodegradation of phenanthrene when the concentration was above $1 \mathrm{CMC}$, which may result from the fact that higher concentrations of rhamnolipids above 1 CMC cause the sequestration of PAHs into surfactant micelles. This phenomenon was further confirmed by the results of FTIR analysis. Rhamnolipids decreased the CSH of GY2B and showed potential for reducing EPS, which affected the uptake of phenanthrene by strain GY2B. In addition, although rhamnolipids did not damage the cell surface, they did not change the ratio of saturated to unsaturated fatty acids during the treatment; thus, it did not enhance the membrane fluidity and transmembrane transport of phenanthrene. These results could provide information to better understand how biosurfactants affect biodegradation of PAHs, which will play an important role in choosing suitable surfactants for the biodegradation of PAHs.

\section{Acknowledgements}

This study was financially supported by the grants received from the Guangdong Provincial Science and Technology Project (2014A020217002 and 2016B020242004).

\section{References}

1 Y. Zhang and S. Tao, Global atmospheric emission inventory of polycyclic aromatic hydrocarbons (PAHs) for 2004, Atmos. Environ., 2009, 43, 812-819.

2 L.-Y. Liu, J.-Z. Wang, G.-L. Wei, Y.-F. Guan, C. S. Wong and E. Y. Zeng, Sediment Records of Polycyclic Aromatic Hydrocarbons (PAHs) in the Continental Shelf of China:
Implications for Evolving Anthropogenic Impacts, Environ. Sci. Technol., 2012, 46, 6497-6504.

3 K. D. Vandermeer and A. J. Daugulis, Enhanced Degradation of a Mixture of Polycyclic Aromatic Hydrocarbons by a Defined Microbial Consortium in a Two-Phase Partitioning Bioreactor, Biodegradation, 2006, 18, 211-221.

4 T. Pantsyrnaya, S. Delaunay, J. L. Goergen, E. Guseva and J. Boudrant, Solubilization of phenanthrene above cloud point of Brij 30: a new application in biodegradation, Chemosphere, 2013, 92, 192-195.

5 E. V. Lau, S. Gan, H. K. Ng and P. E. Poh, Extraction agents for the removal of polycyclic aromatic hydrocarbons (PAHs) from soil in soil washing technologies, Environ. Pollut., 2014, 184, 640-649.

6 S. Laha, B. Tansel and A. Ussawarujikulchai, Surfactant-soil interactions during surfactant-amended remediation of contaminated soils by hydrophobic organic compounds: a review, J. Environ. Manage., 2009, 90, 95-100.

7 J. W. C. Wong, M. Fang, Z. Zhao and B. Xing, Effect of Surfactants on Solubilization and Degradation of Phenanthrene under Thermophilic Conditions, J. Environ. Qual., 2004, 33, 2015-2025.

8 A. K. Haritash and C. P. Kaushik, Biodegradation Aspects of Polycyclic Aromatic Hydrocarbons (PAHs): A Review, J. Hazard. Mater., 2009, 169, 1-15.

9 K. K. Sekhon Randhawa and P. K. Rahman, Rhamnolipid biosurfactants-past, present, and future scenario of global market, Front. Microbiol., 2014, 5, 454.

10 Y. Zhang, W. J. Maier and R. M. Miller, Effect of Rhamnolipids on the Dissolution, Bioavailability, and Biodegradation of Phenanthrene, Environ. Sci. Technol., 1997, 31, 2211-2217.

11 S. A. Churchill, R. A. Griffin, L. P. Jones and P. F. Churchill, Biodegradation Rate Enhancement of Hydrocarbons by an Oleophilic Fertilizer and a Rhamnolipid Biosurfactant, J. Environ. Qual., 1995, 24, 19-28.

12 P. F. Churchill, R. J. Dudley and S. A. Churchill, Surfactantenhanced bioremediation, Waste Manage., 1995, 15, 371377.

13 O. Gonzini, A. Plaza, L. Di Palma and M. C. Lobo, Electrokinetic remediation of gasoil contaminated soil enhanced by rhamnolipid, J. Appl. Electrochem., 2010, 40, 1239-1248.

14 Z. Zhao, A. Selvam and J. W. Wong, Effects of rhamnolipids on cell surface hydrophobicity of PAH degrading bacteria and the biodegradation of phenanthrene, Bioresour. Technol., 2011, 102, 3999-4007.

15 X.-Q. Tao, G.-N. Lu, Z. Dang, C. Yang and X.-Y. Yi, A phenanthrene-degrading strain Sphingomonas sp. GY2B isolated from contaminated soils, Process Biochem., 2007, 42, 401-408.

16 J. J. Ojeda, M. E. Romero-González, R. T. Bachmann, R. G. J. Edyvean and S. A. Banwart, Characterization of the Cell Surface and Cell Wall Chemistry of Drinking Water Bacteria by Combining XPS, FTIR Spectroscopy, Modeling, and Potentiometric Titrations, Langmuir, 2008, 24, 40324040 . 
17 R. S. Makkar and K. J. Rockne, Comparison of synthetic surfactants and biosurfactants in enhancing biodegradation of polycyclic aromatic hydrocarbons, Environ. Toxicol. Chem., 2003, 22, 2280-2292.

18 K. H. Shin, K. W. Kim and E. A. Seagren, Combined effects of $\mathrm{pH}$ and biosurfactant addition on solubilization and biodegradation of phenanthrene, Appl. Microbiol. Biotechnol., 2004, 65, 336-343.

19 Y. Zhang and R. M. Miller, Enhanced octadecane dispersion and biodegradation by a Pseudomonas rhamnolipid surfactant (biosurfactant), Appl. Environ. Microbiol., 1992, 58, 3276-3282.

20 Q. Zhao, J.-Y. Zhang, L.-Z. Chen, J.-X. Zheng, L. Zhao and H.-M. Yin, Cell-surface hydrophobicity and degradation characteristics of hydrophobic hydrocarbon degrading bacteria, Huanjing Kexue, 2005, 26, 132-136.

21 C. O. Obuekwe, Z. K. Al-Jadi and E. S. Al-Saleh, Hydrocarbon degradation in relation to cell-surface hydrophobicity among bacterial hydrocarbon degraders from petroleumcontaminated Kuwait desert environment, Int. Biodeterior. Biodegrad., 2009, 63, 273-279.

22 F. Ahimou, P. Jacques and M. Deleu, Surfactin and iturin A effects on Bacillus subtilis surface hydrophobicity, Enzyme Microb. Technol., 2000, 27, 749-754.

23 X. Wei, W. Jiang, J. Yu, L. Ding, J. Hu and G. Jiang, Effects of $\mathrm{SiO}_{2}$ nanoparticles on phospholipid membrane integrity and fluidity, J. Hazard. Mater., 2015, 287, 217-224.

24 S. Liu, C. Guo, X. Liang, F. Wu and Z. Dang, Nonionic surfactants induced changes in cell characteristics and phenanthrene degradation ability of Sphingomonas sp. GY2B, Ecotoxicol. Environ. Saf., 2016, 129, 210-218.

25 B. She, X. Tao, T. Huang, G. Lu, Z. Zhou, C. Guo and Z. Dang, Effects of nano bamboo charcoal on PAHs-degrading strain Sphingomonas sp. GY2B, Ecotoxicol. Environ. Saf., 2016, 125, 35-42.

26 J. Wingender, T. R. Neu and H.-C. Flemming, Microb. Extracell. Polym. Subst., 1999.

27 A. R. Badireddy, S. Chellam, S. Yanina, P. Gassman and K. M. Rosso, Bismuth dimercaptopropanol (BisBAL) inhibits the expression of extracellular polysaccharides and proteins by Brevundimonas diminuta: implications for membrane microfiltration, Biotechnol. Bioeng., 2008, 99, 634-643.

28 B. Chen, F. Li, N. Liu, F. Ge, H. Xiao and Y. Yang, Role of extracellular polymeric substances from Chlorella vulgaris in the removal of ammonium and orthophosphate under the stress of cadmium, Bioresour. Technol., 2015, 190, 299-306.

29 D. Zhang, J. Wang and X. Pan, Cadmium sorption by EPSs produced by anaerobic sludge under sulfate-reducing conditions, J. Hazard. Mater., 2006, 138, 589-593.

30 G. Guibaud, F. Bordas, A. Saaid, P. D'abzac and E. Van Hullebusch, Effect of $\mathrm{pH}$ on cadmium and lead binding by extracellular polymeric substances (EPS) extracted from environmental bacterial strains, Colloids Surf., B, 2008, 63, 48-54.
31 M. L. Merroun, K. Ben Chekroun, J. M. Arias and M. T. González-Muñoz, Lanthanum fixation by Myxococcus xanthus: cellular location and extracellular polysaccharide observation, Chemosphere, 2003, 52, 113-120.

32 G. Guibaud, S. Comte, F. Bordas, S. Dupuy and M. Baudu, Comparison of the complexation potential of extracellular polymeric substances (EPS), extracted from activated sludges and produced by pure bacteria strains, for cadmium, lead and nickel, Chemosphere, 2005, 59, 629-638.

33 S. Comte, G. Guibaud and M. Baudu, Biosorption properties of extracellular polymeric substances (EPS) towards $\mathrm{Cd}, \mathrm{Cu}$ and $\mathrm{Pb}$ for different $\mathrm{pH}$ values, J. Hazard. Mater., 2008, 151, 185-193.

34 A. A. Henriques Vieira, P. I. Coelho Ortolano, D. Giroldo, M. J. Dellamano Oliveira, T. B. Bittar, A. T. Lombardi and A. L. Sartori, Role of hydrophobic extracellular polysaccharide of Aulacoseira granulata (Bacillariophyceae) on aggregate formation in a turbulent and hypereutrophic reservoir, Limnol. Oceanogr., 2008, 53, 1887-1899.

35 X. Pan, J. Liu and D. Zhang, Binding of phenanthrene to extracellular polymeric substances (EPS) from aerobic activated sludge: a fluorescence study, Colloids Surf., B, 2010, 80, 103-106.

36 L. Qin, G. Zhang, Q. Meng, H. Zhang, L. Xu and B. Lv, Enhanced submerged membrane bioreactor combined with biosurfactant rhamnolipids: performance for frying oil degradation and membrane fouling reduction, Bioresour. Technol., 2012, 126, 314-320.

37 X. Long, Q. Meng and G. Zhang, Application of biosurfactant rhamnolipid for cleaning of UF membranes, J. Membr. Sci., 2014, 457, 113-119.

38 L. H. Kim, Y. Jung, H. W. Yu, K. J. Chae and I. S. Kim, Physicochemical interactions between rhamnolipids and Pseudomonas aeruginosa biofilm layers, Environ. Sci. Technol., 2015, 49, 3718-3726.

39 L. Y. Wick, N. Pasche, S. M. Bernasconi, O. Pelz and H. Harms, Characterization of Multiple-Substrate Utilization by Anthracene-Degrading Mycobacterium frederiksbergense LB501T, Appl. Environ. Microbiol., 2003, 69, 6133-6142.

40 K. Das and A. K. Mukherjee, Differential utilization of pyrene as the sole source of carbon by Bacillus subtilis and Pseudomonas aeruginosa strains: role of biosurfactants in enhancing bioavailability, J. Appl. Microbiol., 2007, 102, 195-203.

41 Z. Hua, J. Chen, S. Lun and X. Wang, Influence of biosurfactants produced by Candida antarctica on surface properties of microorganism and biodegradation of $n$ alkanes, Water Res., 2003, 37, 4143-4150.

42 X. P. Qian, Y. R. Yang and Q. Meng, The effect of biosurfactant on the microbial growth and metabolism, Microbiol. China, 2002, 29, 75-78.

43 F. Qu, H. Liang, J. He, J. Ma, Z. Wang, H. Yu and G. Li, Characterization of dissolved extracellular organic matter (dEOM) and bound extracellular organic matter (bEOM) of Microcystis aeruginosa and their impacts on UF membrane fouling, Water Res., 2012, 46, 2881-2890. 
$44 \mathrm{~F}$. Li and L. Zhu, Surfactant-modified fatty acid composition of Citrobacter sp. SA01 and its effect on phenanthrene transmembrane transport, Chemosphere, 2014, 107, 58-64.

45 X. Huang, K. Peng, L. Lu, R. Wang and J. Liu, Carbon source dependence of cell surface composition and demulsifying capability of Alcaligenes sp. S-XJ-1, Environ. Sci. Technol., 2014, 48, 3056-3064.
46 F. T. Li, H. Yang, Y. Zhao and R. Xu, Novel modified pectin for heavy metal adsorption, Chin. Chem. Lett., 2007, 18, 325-328.

47 J. Yu, M. Tong, X. Sun and B. Li, A simple method to prepare poly(amic acid)-modified biomass for enhancement of lead and cadmium adsorption, Biochem. Eng. J., 2007, 33, 126133. 